\title{
Lessons Learned From Comparing Survival Behaviors Of Very Old Japanese And American Companies
}

Vicki TenHaken, (Email: tenhaken@hope.edu), Hope College

\begin{abstract}
This study compares small and medium-sized U.S. and Japanese companies that have been in business for at least 100 years, looking for common characteristics that enabled them to overcome environmental changes and economic challenges in order to prosper for an unusually long period of time. Working with the premise that a fundamental objective of the corporation is to survive, this work is an attempt to identify common behaviors or strategies among the long-lived companies in different cultures that may be worth emulating.
\end{abstract}

\section{INTRODUCTION}

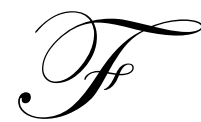

or several years, Professor Makoto Kanda of Meiji Gakuin University in Tokyo has been studying the shinese, or very old Japanese companies, to see if they exhibited certain unique characteristics that enabled their survival for an unusually long period of time. ${ }^{1}$ The companies Kanda studied were established between 718 and 1876. In compiling this database, it was discovered that companies did not have to grow large in order to survive: The shinese companies ranged in size from very small (annual sales volume of 100 million yen or $\sim \$ 1$ million) to large (over 100 billion yen or $\sim \$ 1$ billion), with the average company at 5 billion yen or $\sim \$ 50$ million in annual sales volume. This becomes interesting when one considers how ingrained the maxim of "grow or die" is in American management theory. However, perhaps the most interesting outcome from this study was the profitability of the shinese: the average net profit-to-sales ratio for shinise studied was 5.5 percent. In comparison, the average profit ratio for Japanese companies in general is 2.7 percent, ${ }^{2}$ with the profit/sales ratio of Japanese manufacturing companies at 3.9 percent and 2.2 percent for service firms. Because of these interesting statistics, we conducted further research to identify common behaviors or strategies that may have enabled such long-term success. Once having identified some common behaviors, the question arose as to how culturally specific these results might be: would we see similar common behaviors or strategies in old companies in other countries?

Recently, we have been conducting research on 100-year-old companies in the United States. Though the data base is not yet as large as that of the study of Japanese shinese, and though these studies were not able to obtain as much detailed financial information, ${ }^{3}$ we feel that there is enough information at this date to make some initial comparisons in strategy.

\section{COMMON CHARACTERISTICS OF VERY OLD JAPANESE COMPANIES}

The Japanese companies studied were drawn from a variety of industries, including manufacturing, retail, wholesale, and service firms. Sixty-nine percent of these firms are still owned by the founding family. In 21 percent of the firms studied, descendants of the founding family own a majority of the company. The founding family has some ownership, but less than a majority, in 7 percent of the firms. All the companies are closely held and are not publicly traded. Fifty percent of the companies in this study were 100-150 years old, 20 percent were 150-200 years old, and 30 percent were over 200 years old, with the average company age at 198 years. ${ }^{4}$

How have these companies been able to overcome the many environmental changes and economic challenges to thrive over hundreds of years? Several common strategies were discovered among shinise, which are 
summarized into three categories:

1. Clarity and continuity of corporate culture and values

2. Learning systems built on relationships

3. The ability to balance tradition and innovation through gradual change

\section{Corporate Identify: Clarity And Continuity Of Corporate Culture And Values}

The existence and deliberate transmittal of certain values and beliefs was stated as a key survival factor in 83 percent of the companies studied. Similar to the idea of a "relatively fixed core ideology" identified by Collins and Porras in their book Built to Last, ${ }^{5}$ these values and beliefs function as the fundamental business guidelines for the firm and provide the core ideas around which members of the company identify. Most companies have precepts that were developed by the founder and passed on through the generations. Certain lessons, warnings, and exhortations are described in the precepts. The transference of these company beliefs and guidelines from generation to generation takes various forms, from traditional Japanese poetry, pictures and verbal stories to written documentation. Though the style and content differs from company to company, current leaders consistently confirm the importance of their corporate creed or values as a primary factor in the success of their business. These values and beliefs form the fundamental culture of the business and are used to enhance employee identification with the company. Specific behaviors associated with this characteristic include:

\section{Keep The Business Within The Family}

Even the shortest-lived companies in this research have been managed by three family generations, and the average of all companies studied is seven generations. The founding family was no longer involved in only three percent of the companies.

\section{Maintain The Original Brand Name}

The majority of companies still use both their original company name and the brand name under which they sell their product or service. Some companies (17 percent) had changed the company name, but kept their traditional brand/trade name in the marketplace. The goodwill associated with their traditional brand name was given as a key success factor by over 90 percent of the companies.

\section{Observe Tradition}

These companies are very deliberate about teaching the history of their company as well as their corporate values and beliefs. In addition to teaching history, actually following the corporate philosophy, operating principles and family precepts in the daily operation of their business was stated as an important factor in 67 percent of the companies. For these companies, the traditions aren't just nice stories to share over a cup of tea - they truly guide business decisions.

\section{Inheritance Of Unique Technology}

The existence and protection of a particular technical specialty or core competency was given as a key success factor by 76 percent of the companies studied. These are the company "secrets" or special methodologies that make the organization unique. Such a resource-based strategy that offers differentiation from the competition and is difficult for others to imitate is consistent with J.B. Barney's resource-based theories of competitive advantage.

\section{Traditional Products}

Maintaining traditional products or services was reported as an important strategy by 72 percent of the companies. As we shall see later, this does not mean they don’t also develop new products. 


\section{Focus On Relationships: Learning Systems Built On Relationships}

Relationships are at the core of shinise operations. These companies regard the maintenance of relationships with customers and the development of suppliers from generation to generation as very important to their long-term success. Shinise believe they cannot maintain their success for such long periods of time without the cooperation of others. This emphasis on long-term relationships leads to a kind of symbiosis with organizations outside the company. These relationships have a significant effect on the company's ability to weather environmental challenges as well as their ability to learn and adapt over time. Specific behaviors associated with this characteristic include:

\section{Treat Suppliers And Customers As True Partners}

Since shinise believe they cannot maintain success without the cooperation of others, they put a premium on actions that will retain their suppliers and customers from generation to generation - even if it is at a disadvantage to their own business in the short run. They regard working with vendors to develop the capabilities needed to continue to supply their own organization as an obligation. Continuing to provide long-term customers with the products and services they desire is seen as a sacred duty, even when it is not efficient for the company to do so (and even if it is at times unprofitable). In 75 percent of the companies surveyed, maintaining these long-term relationships with customers and suppliers was stated as a critical factor in their own long-term survival.

\section{Learn From Relationships}

Because shinise view the relationship with their business partners as something more than mere transactions or the trading of goods and services for financial gain, they are willing to share technologies and ideas. This results in mutual learning. Over 80 percent of the companies stated that the development of these business relationships - the willingness to learn from all transaction partners (customers, suppliers and distributors) - is a critical factor in their long-term survival.

\section{Accumulated Technology}

Building on their "inherited unique technology," 66 percent of the companies said the ongoing development of their technological capabilities, internally and with their partners, was also one of their strengths.

\section{Obligation To The Local Community}

Because shinise see themselves as an integral part of a web of relationships connected to their family history and reputation, it would be unthinkable to take actions that would harm their local community. A close connection with their community was listed as an important company characteristic by 71 percent of shinise surveyed.

\section{Gradual Change: The Art Of Balancing Tradition And Innovation}

The image of shinise in Japan is often that they are very conservative, sticking to tradition and resisting change. The reality is that they are aggressive towards change or they would not have survived the many environmental challenges encountered over the centuries. Long-term survival comes from their continuous efforts toward change while protecting their core values. Shinise have precious histories and a heritage they protect at all costs. However, they do not stubbornly observe their traditions without challenge: it is their ability to change by first affirming their traditional past and then altering what is necessary - the balance of tradition and innovation that enables their long lives. The inheritance of unique technology and importance of accumulated technology, form one example of this balance of tradition and innovation. The shinise approach to managing change grows out of the importance to them of maintaining their relationships. To change too rapidly would risk losing customers or suppliers - any sudden, radical change on their part could jeopardize the health of other partners in the system as well as their own. Shinise understand that they are part of a large, interdependent system. While aggressively 
pursuing internal change, they patiently work with employees and their external partners so no one is left behind once the change is implemented. The systemic effect of this is to reinforce the loyalty of customers and the dedication of distributors, suppliers and employees to the success of the company. Thus they are able to survive upheavals in their industry, advances in technology, and other environmental changes while retaining loyal customers and a close relationship with their suppliers. This characteristic manifests itself in the following behaviors:

\section{Up-To-Date Management Methods}

In contrast to their old-fashioned stereotype, 88 percent of shinise surveyed said the continual modernization of their management systems was critical to their long-term survival.

\section{Search For New Suppliers And Customers}

Just because they value the relationships with old and existing partners does not mean shinise aren't also working to find new suppliers and new customers. Nearly 80 percent of the companies said the development of new business relationships was an important factor in their survival.

\section{Focus On Developing New Products And Businesses}

Though not as critical a behavior as some previously mentioned, 57 percent of the companies said developing new products was an important factor in their long-term survival.

\section{Characteristics Of Shinise Discussion}

A basic objective of shinise is survival and there are common behaviors that are employed by these very old companies that help ensure their continued survival. Additionally, these strategies appear to result in enhanced profitability but may deter growth, if the size of these firms is any indication. For instance, brand continuity is reported to be an important strategy for these companies. Though maintaining an old brand name may not be the way to gain market share or growth in scale, it does appear to positively affect profitability. When a company wants to increase sales volume for old product lines, they may believe the way to do so is to update and change the brand name; and this may indeed increase sales and market share - but not necessarily profitability. Although Japanese firms have a tendency to seek market share first and profit later, shinise behave to the contrary. And the result is that shinise are significantly more profitable than the average Japanese company. ${ }^{6}$

\section{COMMON CHARACTERISTICS OF VERY OLD U.S. COMPANIES}

Over the last 12 months, we have been studying companies in the United States that are over 100 years old to identify common behaviors or strategies that may have played a role in their survival. ${ }^{7}$ Fifty percent of the companies in the U.S. study were 100-125 years old and half were over 125 years old. The oldest companies included in the study were established in 1860. The average age of the U.S. companies studied was $128-70$ years less than the average age of the Japanese shinise. Half of the U.S. companies studied were also very small, with sales of less than $\$ 2$ million per year. Ten percent were over $\$ 2$ million but less than $\$ 10$ million; another ten percent are in the $\$ 10$ to $\$ 50$ million range. Twenty percent reported annual sales of $\$ 50$ to $\$ 150$ million, and ten percent over $\$ 150$ million, with the largest at $\$ 300$ million.

As with the Japanese companies, all of the companies in this study were privately held, though one had been public at one time and management later did a leveraged buy-out. Half of the firms were still owned by members of the founding family - one in the seventh generation. Of the half that were not still owned by members of the founding family, three-fourths are already into multiple generations of the current family ownership - two in the fourth generation and one in the fifth. All of them indicated that remaining a private firm was an important factor in their long-term survival, though "keeping the business in the family" was not as strong a factor. 
How did these companies overcome many environmental changes and economic challenges to thrive over one hundred years? Four common strategies were identified:

1. Focus strategy

2. Investments in long-term and loyal employees

3. A service orientation

4. Driven by core values

\section{Focus Strategy}

All companies surveyed indicated that a focus strategy was an important factor in their firm's long-term survival. Three-quarters of the companies surveyed said that having a particular business focus or niche in which they have built a reputation was "extremely important;" the other 25 percent said such a focus strategy was "important." Sixtey-two percent of the companies reported that keeping focused on their main business was "extremely important," with the other 38 percent saying it was "important."

One common practice that is a result of this strategy is that nearly 90 percent of the companies have retained the same company name under which the business was founded, even when it was a family name and a new family purchased the company. Once a reputation was built, the companies were reluctant to change the name under which the company did business, even if it was named after a founder whose family was no longer involved in the company.

Though some companies surveyed indicated they had sought new business opportunities over the years, growth was not a driving force. In fact, 40 percent of the companies said they have not actively sought to grow their business; and of the 60 percent who did, none of them said it was "extremely important" in their firm's success. For most firms, keeping focused on the business where their reputation had been built was more important than growth, particularly if growth meant branching out into new areas.

\section{Employees Truly Are Their Most Important Asset}

Almost all (88 percent) of the companies surveyed indicated that having loyal, long-term employees was a critical factor in their firm's success and long-term survival. Echoing the responses to the question of "keeping focused on their main business," two-thirds of the companies said that having loyal, long-term employees was "extremely important."

A common practice reported by these companies was keeping employees on the payroll even when they didn't have enough work to keep them productively employed. Almost all of the companies surveyed said they had done this and of those who had, all indicated it was either an "extremely important" (50 percent) or "important" factor (50 percent) in their company's long-term success.

Another practice many companies said they employed in carrying out this strategy was to pay above average compensation. Some said that, since they were a small business, there was no way they could afford to pay employees "what they were really worth" but they offered other benefits, such as flexible work hours, to make their company an attractive place to work and to retain employees. Interestingly, 88 percent of the companies surveyed said they have some form of profit-sharing or bonus plan in place for employees. Half felt this was an "extremely important" factor in the firm's long-term survival and 38 percent said it was "important."

But, strange as it may seem, this strategy is perhaps best exemplified by a manufacturing firm that has actually shut down its U.S.-based manufacturing facility and shifted to all off-shore vendors to produce their products. After the announcement to employees about our discontinuing production in the U.S., three TV stations and two newspapers showed up at the plant. The company president and current owner said he couldn't deal with all of them, so he gave the news teams the run of the place. "They took full advantage of the opportunity, interviewing and filming dozens of employees. The TV reporter said he's covered over 100 plant closings and this was the only one where not one person had a bad thing to say about the company. He concluded his evening news 
report with this: 'They say your name doesn't have to be on the door to be part of this family company. You get the feeling it's really that way.' Following this announcement, productivity at the factory actually went up! Quality reached levels of near perfection. When employees were asked about this, they related a determination to make products they could always be proud of and to finish well. When people and communities live through the trauma of reshaping business models to respond to world competition, it's only human to wonder: Is it fair? Shouldn't we do something to stop this or at least slow it down? People are getting hurt...this can't be right. We must help each other through these transitions. We know these changes are good for each of us and all Americans in the long run. Reinvention frees us up to productively invest our time in ways that are more highly valued in the marketplace. But in the short run it takes gobs of energy and determination to learn new skills and apply them in new ways. It's important to encourage each other through the transition. Fifteen area companies worked closely with us to identify where job openings matched the skills and ambitions of our people. Many of those businesses interviewed our people on site. Most people affected by our plant closing have landed on their feet."

\section{Service, Service, Service}

The only other strategy that scored consistently high among all companies surveyed was customer service. Eighty-eight percent said that maintaining close relationships with their traditional customers was an "extremely important" factor in their firm's long-term survival and the other twelve percent said it was "important." It was interesting, however, that only one-third of the companies indicated that investing in developing new customers was "extremely important" (and some were quite neutral - or even negative - on the whole idea of advertising or market development).

Perhaps the practice that is most indicative of this strategy is that all of the companies said that they had continued to offer products or services that their traditional customers valued, even if they didn't make any money or even lost money - doing so. They saw this as an important factor in retaining customer loyalty. Similar to keeping employees on the payroll, even when they didn't have work to keep them busy, these companies would do whatever they needed to keep their loyal customers, even if it did not appear to be a financially sound decision for the business in the short term. Stories abound of going to great lengths to meet customer needs, however, small. One retailer said they lived by the motto "We treat a kid with 10 cents to spend the same as an adult with $\$ 50$."

\section{Driven By Core Values}

Though 88 percent of the companies indicated they had strong company values or beliefs, few had written statements of these core values and some had difficulty expressing them succinctly (and a few weren't even sure what the interviewers were talking about). However, most had strong oral traditions that they represented in sayings such as "When the store is open there's always a Fabiano on the floor" or "The customer is always \#1 - that means you call them by their name." Some were simply common sayings such as "We follow the Golden Rule" or "Be fair and honest" or "We don't play pricing games - we offer a good, first deal."

There were no common practices identified among companies to support this strategy. The company values were not written documents and the companies did not indicate there was a deliberate effort to teach them to new employees. These "values" seemed to be more a way of doing business that was instilled in employees through the owners' behaviors; since most of the companies had employees that were also with the company for a long time, their behaviors just tended to embody these values as well.

\section{COMPARISON OF VERY OLD JAPANESE AND U.S. COMPANIES}

So what can we conclude regarding commonalities between very old Japanese companies and small and medium sized old U.S. companies? Though the strength and content of their survival strategies vary, there are some similarities.

The Japanese companies believed the existence and deliberate transmittal of certain values and beliefs was a critical factor in their survival. Though many of the old U.S. companies had oral traditions that indicated the 
existence of a corporate culture, this factor was not nearly as strong in the U.S. companies.

The most prevalent common strategy in U.S. companies was that of focus. A similar focus strategy was not readily apparent in the Japanese study. However, the strength of such factors as "the inheritance of unique technology" and "maintaining the original brand name" may be indicative of a focus strategy. Some initial followup has indicated that many of the Japanese companies have, indeed, remained focused on a particular area of business, but others have branched out and diversified over time.

The shinise strategy of engaging in learning systems based on relationships correlates very closely to the U.S. companies' strategies of service orientation and investments in loyal, long-term employees. In both cases, customers and employees are seen as partners in the business rather than as mere "hired hands" or agents in the exchange of goods or services for monetary gain. However, the Japanese companies extended this relationship strategy to include suppliers as well and the U.S. companies did not exhibit a similar consistent strategy in this area. Though some U.S. companies indicated that ties to their local community were a critical factor in their long-term success, many more Japanese companies listed this as a key survival factor.

The shinise ability to balance tradition and innovation through gradual change is a more difficult one to compare to U.S. companies. In the U.S. study we found that companies were either proudly old-fashioned and traditional - and laughed at questions such as whether they "regularly seek to modernize management methods and processes" - or were very up-to-date in terms of products, processes and technology. Though it is doubtful that any of them would have survived over 100 years without being able to adapt to changes, there did not seem to be the same level of appreciation for the artful 'balance' of tradition and innovation that the shinise exhibited.

\section{CONCLUSIONS AND RECOMMENDATIONS}

A fundamental objective of the firm, though often unstated, is survival. Companies focus on being profitable, but the underlying reason for making a profit is to continue to "live," or stay in business. However, most firms do not "live" as long as they could. A Royal-Dutch Shell study described in The Living Company calculated the average life expectancy of a large multinational corporation at 40 to 50 years. In some countries, 40 percent of all newly created companies last less than 10 years. ${ }^{9}$ A 1996 study by Stratix Consulting Group calculated the average life expectancy of firms in Japan and much of Europe, regardless of size, at 12.5 years. A 2004 study by Hewitt Associates indicated the average life span of companies today is 12-15 years. In contrast, the firms in these studies have "lived" well over 100 years.

By identifying, monitoring and acting on the right factors, the average human life span has increased over 80 percent in just one century. ${ }^{10}$ Humans have learned what behaviors increase longevity: a balanced diet, regular exercise, monitoring blood pressure and cholesterol, etc. If the life expectancy of a person can increase through the identification of longevity factors, why can't a company's?

It is not just the owners or investors in a company that profit from an organization's survival, but employees, customers, suppliers, and communities all benefit as well. The purpose of this study is to identify crosscultural corporate behaviors that new companies hoping to survive long into the future can incorporate into their strategies. It is our belief that a company desiring a long, profitable life may benefit by learning about the behaviors of the long-lived firms in this study: If the life expectancy of a person can increase through the identification of longevity factors, why can't a company's?

\footnotetext{
${ }^{1}$ Iwasaki, N. and Kanda, M. 1996. Sustainability of the Japanese Old Established Companies, Economic Institute of Seijo University. Vol. 132: 160-130

2 Japan Ministry of Finance, 2004.

${ }^{3}$ All U.S. firms studied are privately-held; many of their leaders were reluctant to share profitability data.

${ }^{4}$ Kanda, M and TenHaken, V. November 2006. Survival Strategies of Old Japanese Companies and Their Effect on Firm Growth and Profitability, Proceedings of the Association for Global Business Annual Conference, Volume 18, ISBN: 1050-6292, paper \#46.
} 
${ }^{5}$ Collins, J.C. and Porras, J. I. 1994. Built to Last. Harper Collins Publishers, Inc. New York, NY, 44. The average age of the "visionary" companies profiled in this book was 92 years.

${ }^{6}$ Japan Ministry of Finance, 2004. The profit/sales ratio of Japanese manufacturing companies is $3.9 \%$ and $2.2 \%$ for service firms compared to $5.5 \%$ for shinise.

7 TenHaken, V. and Cohen, E. 2007. Survival Behaviors of 100-Year-Old West Michigan Retail and Service Companies, Journal of Business and Economics Research. 2007. Information from interviews with manufacturing firms has been added to the data described in this paper.

${ }^{8}$ Interview with Robert L. Sligh, Jr., Chairman, CEO and President, Sligh Furniture Company, August, 2006.

${ }^{9}$ de Gues, A. 1997 The Living Company, 2.

${ }^{10}$ The average human life span has risen from a life expectancy of 40 in the early 1900 s to 75 years at the turn of the century. 2004, Hewitt Quarterly Asia Pacific, 3.

\section{REFERENCES}

1. Barney, J.B. 2001. Resource-based theories of competitive advantages: A ten-year retrospective on the resource-based view, Journal of Management, 27, 643-650.

2. $\quad$ Business Basics: People \& Performance. 2004. Hewitt Quarterly Asia Pacific.

3. Collins, J., Porras, J. 1994. Built to Last: Successful Habits of Visionary Companies. HarperCollins Publishers, Inc: New York, NY.

4. de Geus, A. 1997. The Living Company. Harvard Business School Press: Boston MA.

5. Iwasaki, N, Kanda, M. 1996. Sustainability of the Japanese Old Established Companies. Economic Institute of Seijo University 132: 160-130.

6. TenHaken, V. and Cohen, E. 2007. Survival Behaviors of 100-Year-Old West Michigan Retail and Service Companies, Journal of Business and Economics Research. 2007.

\section{NOTES}

